\title{
Lung abscess secondary to lung cancer with Eikenella corrodens and Streptococcus anginosus: a case report
}

\author{
Leihao $\mathrm{Hu}^{1 \dagger}$, Jietao $\mathrm{Lin}^{2 \dagger}$, Jing $\mathrm{Li}^{1,3,4}$, Yang $\mathrm{CaO}^{2^{*}}$ and Lizhu Lin ${ }^{2^{*}}$ (D)
}

\begin{abstract}
Background: Eikenella corrodens and Streptococcus anginosus, which are primary colonization bacteria of the normal flora of the oropharynx, are infrequent bacteria, especially the former. Here, we report a case of lung abscess with a coinfection of Eikenella corrodens and Streptococcus anginosus in a lung cancer patient.
\end{abstract}

Case presentation: A 66-year-old Chinese man with lung cancer was admitted to the hospital, complaining of a cough and expectoration for five months and fever for two months. After a series of inspections to differentiate a cancer-related fever from an infectious fever, he was diagnosed with lung abscess. Draining pus culture demonstrated Eikenella corrodens and Streptococcus anginosus. After more than 1 month of antibiotic therapy and draining in total, he gradually recovered to fight against lung cancer.

Conclusion: This report highlights the increased pathogenicity of Eikenella corrodens and Streptococcus anginosus in an immunocompromised cancer patient, especially after a few invasive operations. Additionally, even though a patient has been diagnosed with cancerous fever, strong vigilance is needed in case an infection arises.

Keywords: Eikenella corrodens, Streptococcus anginosus, Lung abscess, Lung cancer, Case report

\section{Background}

In over $90 \%$ of cases of lung abscess, polymicrobial bacteria can be found. For decades, anaerobic bacteria have been the most dominant type of bacteria in lung abscesses, with Streptococcus, including Streptococcus anginosus [1]. Eikenella corrodens, also a kind of anaerobic bacteria, has been reported to cause lung abscess in only several cases [2-7]. Eikenella corrodens has been previously found to be associated with lung abscess in a lung cancer patient [8]. Coinfection with Eikenella corrodens and Streptococcus has been reported to cause abscesses in different body parts, including the liver, thigh and brain [9-11]. The two uncommon fastidious bacteria are

\footnotetext{
*Correspondence: 393556828@qq.com; lizhulin26@yahoo.com

'Leihao Hu and Jietao Lin contributed equally to this work.

${ }^{2}$ Oncology Center, the First Affiliated Hospital of Guangzhou University of Chinese Medicine, Guangzhou, Guangdong, China

Full list of author information is available at the end of the article
}

both part of the normal microbiota of mucosa in humans $[12,13]$. Sometimes, clinicians may not be able to easily differentiate a cancer-related fever and an infectious fever. Here, we report a case of lung abscess secondary to lung cancer with a coinfection of Eikenella corrodens and Streptococcus anginosus.

\section{Case presentation}

A 66-year-old Chinese man was admitted to the Tumor Center of the First Affiliated Hospital of Guangzhou University of Chinese Medicine on September 21, 2018, complaining of a cough and expectoration for 5 months and fever for 2 months. During the period of visiting the outer hospital, chest and upper abdomen computed tomography (CT) scans were performed on April 26, showing a lung mass in the left inferior lung (size of approximately $45 \times 43 \mathrm{~mm}$ ) with some lymph node metastasis (including bilateral peribronchial lymph nodes,

(C) The Author(s). 2020 Open Access This article is licensed under a Creative Commons Attribution 4.0 International License, which permits use, sharing, adaptation, distribution and reproduction in any medium or format, as long as you give appropriate credit to the original author(s) and the source, provide a link to the Creative Commons licence, and indicate if changes were made. The images or other third party material in this article are included in the article's Creative Commons licence, unless indicated otherwise in a credit line to the material. If material is not included in the article's Creative Commons licence and your intended use is not permitted by statutory regulation or exceeds the permitted use, you will need to obtain permission directly from the copyright holder. To view a copy of this licence, visit http://creativecommons.org/licenses/by/4.0/ The Creative Commons Public Domain Dedication waiver (http://creativecommons.org/publicdomain/zero/1.0/) applies to the data made available in this article, unless otherwise stated in a credit line to the data. 
PBLN). CT-guided percutaneous biopsy and two endobronchial ultrasound-guided transbronchial needle aspiration (EBUS-TBNA) procedures were carried out for the biopsy in April. The pathology was adenocarcinoma. However, the patient refused to receive regular anticancer therapy until August. On August 1 and August 22, two courses of chemotherapy (tegafur gimeracil oteracil potassium capsule and carboplatin) were conducted, although low fever began in July. The prophylactic antibiotic was administered though the white blood cell count (WBCC), procalcitonin (PCT) and C-reactive protein (CRP) levels were in the normal range, after which there was defervescence. Based on his properties of fever, he was clinically diagnosed with cancer-related fever. In mid-September, the third chemotherapy was delayed to a vague later date because of a high fever, high WBCC and CRP levels, and severe myelosuppression when a chest CT showed a cyst cavity with the gasliquid level in the left lung. Therefore, the patient was diagnosed with lung abscess and subsequently accepted antibiotic therapy and percutaneous abscess drainage. However, there was obstructed drainage and no symptom relief. The patient visited our oncology centre for further treatment.

Once admitted, the patient underwent re-examination by CT, revealing extensive hydropneumothorax, and was then diagnosed with pyothorax. Moreover, laboratory inspection including high WBCC, CRP, PCT and low albumin levels, indicating infection and malnutrition. We adjusted the depth of the catheter that had been put in by the previous hospital and conducted closed thoracic drainage, after which the patient underwent a chest Xray (Fig. 1). We empirically used intravenous moxifloxacin beginning on September 21. In addition, the blood culture results were negative. We ordered bacterial cultures four times for the draining pus, and each result was positive; the bacteria that grew included Eikenella corrodens and Streptococcus anginosus (Figs. 2, 3). There was no improvement in symptoms. Thus, on September 26, we added piperacillin-tazobactam with moxifloxacin to cover the pathogens. However, the response was not good until the bacterial susceptibility test was determined on September 28. According to the outcome, we changed piperacillin-tazobactam with cefoperazone sulbactam because the bacteria were resistant to penicillins. Concurrently, we began thoracic washing with povidone iodine and metronidazole sodium chloride solution heated to physical body temperature (for a total of 6 days, twice per day), and we encouraged him to blow up balloons to enhance the draining (Fig. 4). Echocardiography was performed on September 28, and the results showed that heart structure and function were both normal; therefore, we ruled out endocardial infection. Subsequently, the patient became afebrile, and the draining

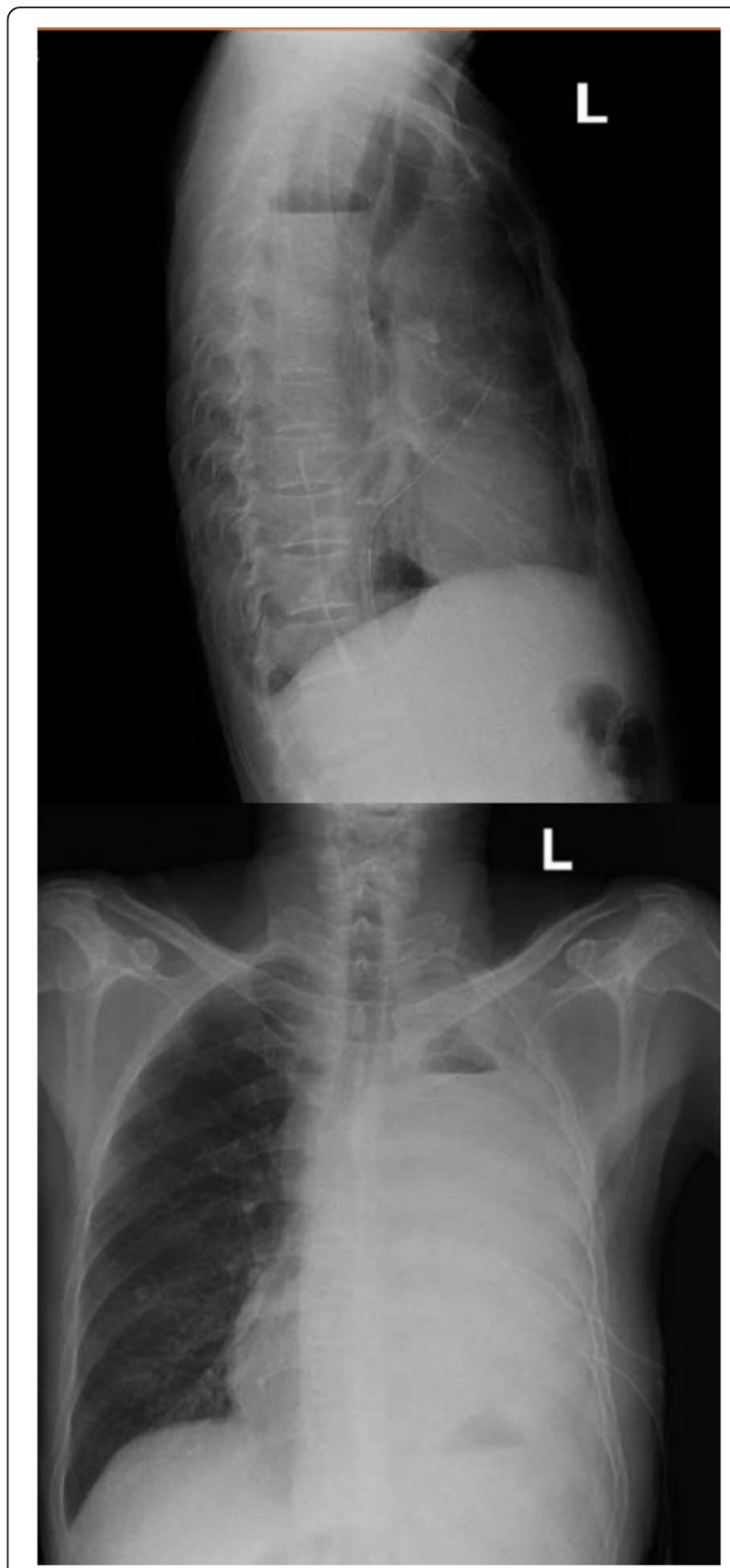

Fig. 1 Chest $X$-ray image after the patient underwent closed thoracic drainage. It showed extensive hydropneumothorax (massive pleural effusion) with atelectasis

solution became cleared and tailed off. On October 18, the WBCC and CRP levels were in the normal range, and then he was discharged after more than 4 weeks of parenteral antibiotic therapy and thoracic draining.

Moreover, 7 days of oral moxifloxacin was prescribed as discharge medication. Nutrition support was run throughout the whole medication period. From a telephone follow-up in December, we were informed that 


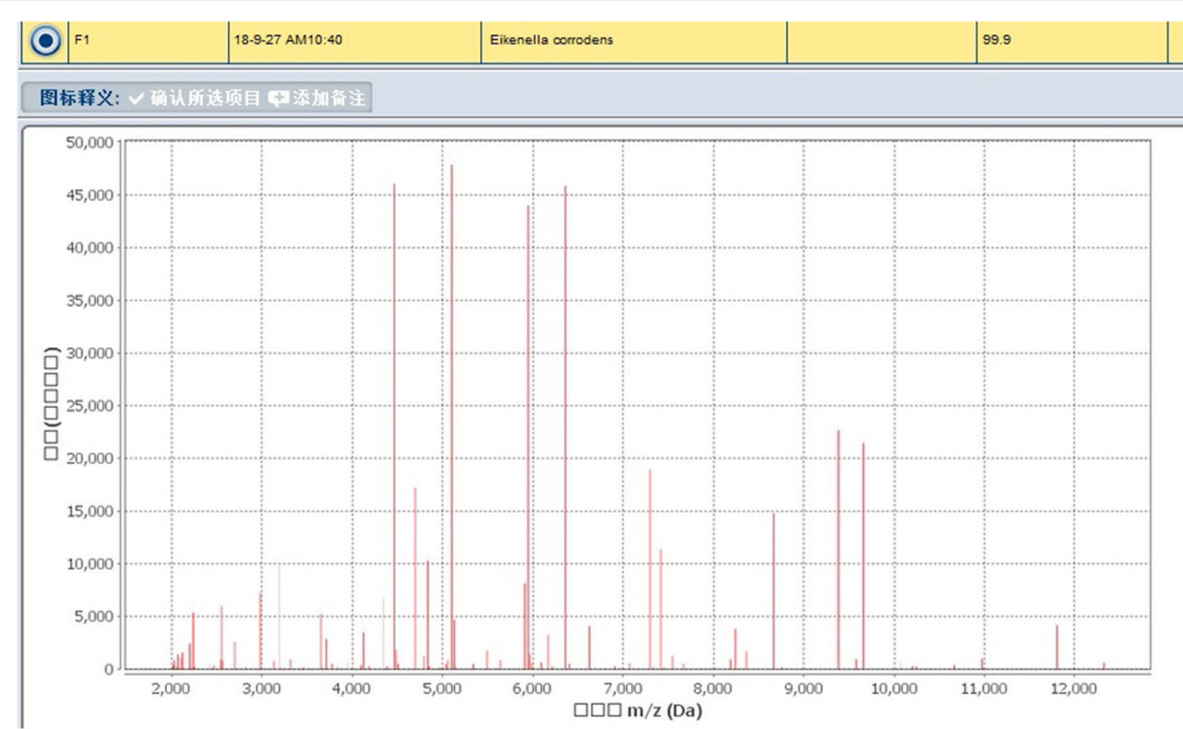

Fig. 2 The outcomes of the microorganism mass spectrometer indicated that Eikenella corrodens and Streptococcus anginosus existed

the latest CT scan showed complete removal of the abscess and that he was undergoing further anti-tumour therapy.

\section{Discussion and conclusions}

The aetiology, diagnosis and treatment options of lung abscess have been summarized [1]. Targeted antibiotics and thorough drainage are key to cure. As mentioned, with the extensive use of antibiotics, the mortality of lung abscesses has decreased to approximately $2-38.2 \%$ with the important roles of patient age, malnutrition, comorbidity, immunity, appropriate and timely antibiotics, and supportive therapy. Nevertheless, for a cancer patient, a lung abscess can be fatal because it worsens the patient's condition and interferes with the anticancer treatment. Diagnosis and treatment must be determined as soon as possible to increase the time to fight against the cancer.

In the present case, contributing factors to lung abscess were elderly age, malnutrition, hypoimmunity due to the tumour and previous chemotherapy, bronchial obstruction related to the lung mass and enlarged PBLN, and multiple biopsies. Eikenella corrodens and Streptococcus anginosus, which are primary colonization

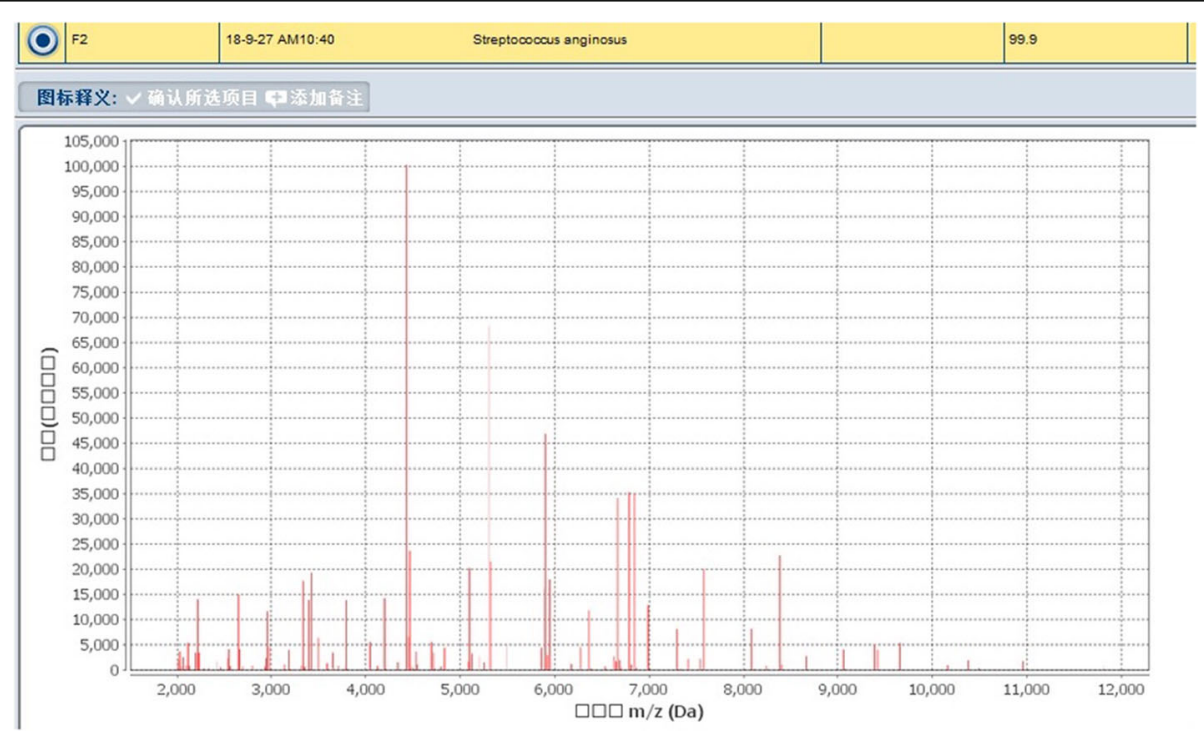

Fig. 3 The outcomes of the microorganism mass spectrometer indicated that Eikenella corrodens and Streptococcus anginosus existed 


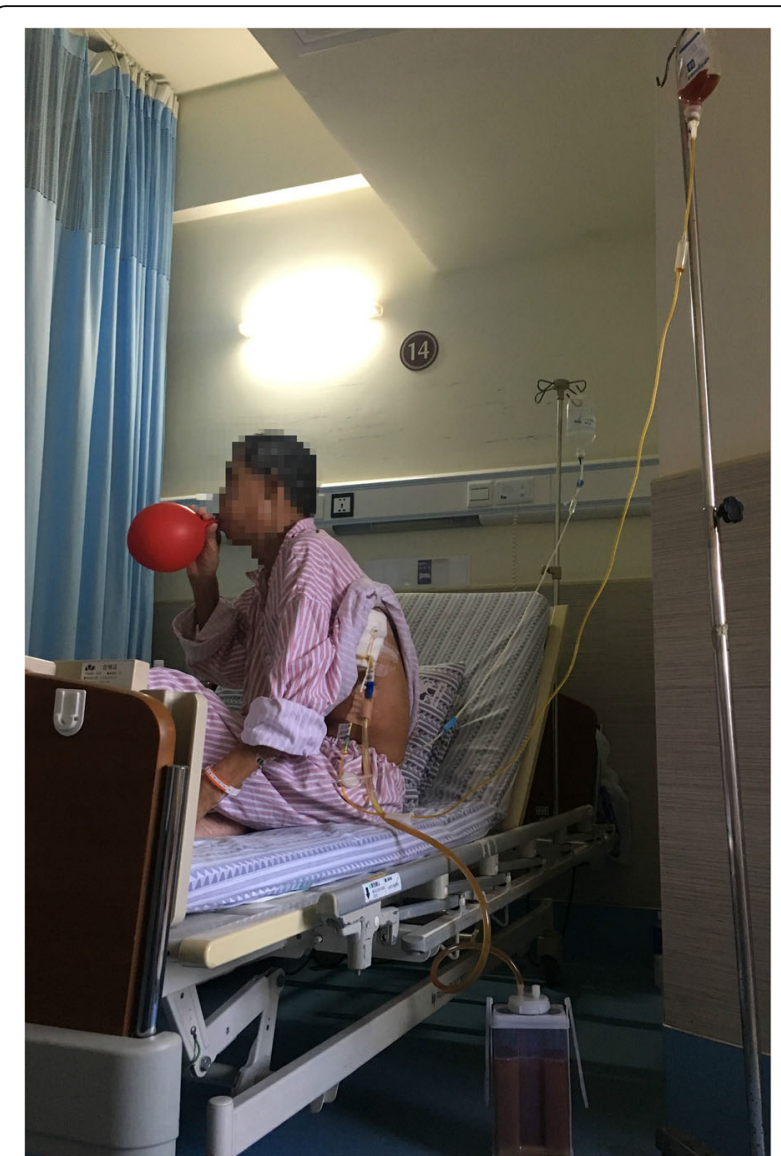

Fig. 4 The patient was excepting thoracic washing with povidone iodine and metronidazole sodium chloride solution heated to physical temperature (for a total of 6 days, twice per day) and was encouraged to blow up balloons to enhance the draining

bacteria of the mucosa, were isolated from the abscess. It is possible that the route of coinfection was via bronchi, and multiple biopsies, especially EBUS-TBNA, prompt the formation. There is a small chance that drainage may permit entry of the microorganisms into the cavity or haematogenous seeding.

Clinically, early signs and symptoms, including cough, expectoration, fever, weight loss, fatigue, chest pain, cannot effectively differentiate pneumonia, lung abscess, and lung cancer, which requires clinicians a have a keen observation for the condition. In this case, the expedited diagnosis and timely CT examination were the important aspects to differentiate a cancer-related fever from an infectious fever without delay. Thorough drainage, thoracic wash and rational choice of antibiotics give rise to recovery. Repetitive bacterial culture with pus even though the blood culture results were negative, which might be suppressed by antibiotics, helps us to obtain specific pathogens, which instructs us to use antibiotics. Notably, both Eikenella corrodens, a member of HACEK bacteria, and Streptococcus anginosus, a member of
Streptococcus viridans, are significant infecting organisms for infective endocarditis [14]. Therefore, we performed echocardiography.

Overall, multiple invasive operations may enhance the possibility of opportunistic infection. To determine the pathogenic bacterium, the draining pus should be captured again despite the negative blood culture results. Even if Eikenella corrodens and Streptococcus anginosus have limited pathogenicity, they are potential pathogens for lung abscesses. The finding of Eikenella corrodens, a member of the HACEK group, and Streptococcus anginosus, a member of Streptococcus viridans, should cause observation of endocarditis even in patients without obvious symptoms of endocarditis. Moreover, clinicians need to pay attention to the prevention and differentiation of cancer-related and infectious fevers in cancer patients. The faster we make it clear, the more time we will buy for anticancer treatment.

\section{Abbreviations}

CT: Computed tomography; PBLN: Peribronchial lymph nodes; WBCC: White blood cell count; PCT: Procalcitonin; CPR: C-reactive protein

\section{Acknowledgements}

Thanks to the Dr. Weizhen Guo and Dr. Danhua Li for professionmal explaination of the bacteria.

\section{Authors' contributions}

Medical guide: LZL, YC, JTL. Conceptualization and Data collection: LHH, JTL, JL. Writing - original draft: LHH. Writing - review \& editing: LZL, YC, JTL, JL. ${ }^{\triangle} \mathrm{LHH}$ and JTL are equal contributors. All authors have read and approved the manuscript.

\section{Funding}

The Natural Science Foundation of Guangdong Province China (Grant No. 2018B030311023); The research team project of innovative hospital in the First Affiliated Hospital of Guangzhou University of Chinese Medicine (2017TD01). The two funding bodies support the publication fee for us and have no role in the design of the study and collection, analysis, and interpretation of data and in writing the manuscript.

\section{Availability of data and materials}

All the data and materials in this report are from the authors on reasonable request.

Ethics approval and consent to participate Not applicable.

\section{Consent for publication}

Written informed consent was obtained from the patient for publication of this report and any accompanying images.

\section{Competing interests}

All the authors declare there are no conflicts.

\section{Author details}

${ }^{1}$ First Clinical Medical College, Guangzhou University of Chinese Medicine, Guangzhou, Guangdong, China. ${ }^{2}$ Oncology Center, the First Affiliated Hospital of Guangzhou University of Chinese Medicine, Guangzhou, Guangdong, China. ${ }^{3}$ Guangzhou University of Chinese Medicine, Guangzhou, Guangdong, China. ${ }^{4}$ Oncology Department, the First Affiliated Hospital of Hunan University of Chinese Medicine, Changsha, Hunan, China. 
Received: 24 February 2019 Accepted: 27 April 2020

Published online: 18 May 2020

\section{References}

1. Kuhajda I, Zarogoulidis K, Tsirgogianni K, Tsavlis D, Kioumis I, Kosmidis C, Tsakiridis K, Mpakas A, Zarogoulidis P, Zissimopoulos A, et al. Lung abscessetiology, diagnostic and treatment options. Ann Transl Med. 2015;3(13):183.

2. Sawatari K, Mochida C, lori F, Hayashi A, Nasu M. Bacteriological study on Eikenella corrodens isolated from pulmonary puncture fluid of lung abscess (author's transl). Rinsho Byori. 1977;25(7):597-602.

3. Goldstein EJ, Kirby BD, Finegold SM. Isolation of Eikenella corrodens from pulmonary infections. Am Rev Respir Dis. 1979;119(1):55-8.

4. Hsu CY, Liu LL, Luh KT. Lung abscess caused by Eikenella corrodens: report of a case. Taiwan Yi Xue Hui Za Zhi. 1989;88(8):828-31.

5. Miguelez M, Dominguez-Ortega L, Del PMA, Garcia AJ. Multiple pulmonary abscesses caused by Eikenella corrodens. Rev Clin Esp. 1992;191(2):115-6.

6. Kentos A, De Vuyst P, Stuelens MJ, Jacobs F, de Francquen P, Delaere B, Demaeyer P, Thys JP. Lung abscess due to Eikenella corrodens: three cases and review. Eur J Clin Microbiol Infect Dis. 1995;14(2):146-8.

7. Hironaka M, Ohta M, Oda T, Kamei T, Kitamura S. A case of lung abscess caused by Eikenella corrodens. Nihon Kokyuki Gakkai Zasshi. 1998;36(2):16470.

8. Javaheri S, Smith RM, Wiltse D. Intrathoracic infections due to Eikenella corrodens. Thorax. 1987:42(9):700-1.

9. Quinlivan D, Davis TME, Daly FJ, Darragh H. Hepatic abscess due to Eikenella corrodens and Streptococcus milleri: implications for antibiotic therapy. J Infect. 1996;33(1):47.

10. Zhiyong Z, Xiufang $L$, Jiajie $L$. Thigh abscess caused by Eikenella corrodens and Streptococcus intermedius: a case report. J Infect. 2007;54(1):17-9.

11. Canton P, Schaefer JL, May T, Gerard A, Voiriot P, Maury F, Dureux JB. Abces cerebral a Eikenella Corrodens. Med Mal Infect. 1987;17(6):385-8.

12. Poole PM, Wilson G. Occurrence and cultural features of Streptococcus milleri in various body sites. J Clin Pathol. 1979:32(8):764-8.

13. Perez TE, Garcia AJ, Cilla EG, de Toro RP. Extraoral origin of Eikenella corrodens infection. LANCET. 1988;1 (8580):298-9.

14. Habib G, Lancellotti P, Antunes MJ, Bongiorni MG, Casalta JP, Del ZF, Dulgheru R, El KG, Erba PA, lung B, et al. 2015 ESC guidelines for the management of infective endocarditis: the task force for the management of infective endocarditis of the european society of cardiology (esc). endorsed by: european association for cardio-thoracic surgery (eacts), the european association of nuclear medicine (EANM). Eur Heart J. 2015;36(44): 3075-128.

\section{Publisher's Note}

Springer Nature remains neutral with regard to jurisdictional claims in published maps and institutional affiliations.

Ready to submit your research? Choose BMC and benefit from:

- fast, convenient online submission

- thorough peer review by experienced researchers in your field

- rapid publication on acceptance

- support for research data, including large and complex data types

- gold Open Access which fosters wider collaboration and increased citations

- maximum visibility for your research: over $100 \mathrm{M}$ website views per year

At BMC, research is always in progress.

Learn more biomedcentral.com/submissions 